\title{
Heat- and corrosion-resistant catalytic materials for environmental and energy applications
}

\author{
Masato MACHIDA ${ }^{1,2, \dagger}$ \\ ${ }^{1}$ Division of Materials Science and Chemistry, Faculty of Advanced Science and Technology, Kumamoto University, \\ 2-39-1 Kurokami, Chuo, Kumamoto 860-8555, Japan \\ ${ }^{2}$ Elements Strategy Initiative for Catalysts \& Batteries (ESICB), Kyoto University, \\ 1-30 Goryo-Ohara, Nishikyo, Kyoto 615-8245, Japan
}

\begin{abstract}
Heat- and corrosion-resistant catalytic materials are essential in the field of environmental protection and energy production. In this article, recent progress in material research in this field is reviewed based on publications from the author's research group. In an automotive three-way catalyst (TWC), thermal deactivation by sintering of platinum group metal (PGM) nanoparticles can be suppressed by controlling the interfacial bonding to the surface of the support, which provides an anchoring effect. A similar concept is useful in solar thermochemical cycles to produce clean fuels, which are conducted in a high-temperature and corrosive environment containing sulfuric acid vapor. A further challenge in both applications is the replacement of PGM catalysts by economically viable catalysts. Thermally stable multicomponent transition metal oxides were proposed as a possible candidate for PGM-free TWC. A positive synergy between the different functionalities of metal elements results in high catalytic performance. Molten phases of metal vanadates, which are used for solar thermochemical cycles of sulfur, are another example of PGM-free catalysts. These examples highlight the critical roles of each metal element and their combination for obtaining synergy, which are required to further understand the ways to simultaneously achieve catalytic activity and thermal/corrosion stability.
\end{abstract}

(02021 The Ceramic Society of Japan. All rights reserved.

Key-words : Catalyst, Support, Sintering, Three-way catalyst, Solar thermal energy

[Received February 1, 2021; Accepted March 1, 2021]

\section{Introduction}

Ceramic materials are used as catalysts (active components), supports (washcoats), and substrates (monolithic honeycombs) in a wide range of industrial chemical processes. ${ }^{1)}$ An active component comprises metals and/or metal oxides, whereas a support mainly comprises metal oxides whose primary role is to ensure high dispersion of active components and inhibit the loss of specific surface area during a long period of operation. Therefore, depending on the process temperature, thermal stability against sintering should be an essential characteristic of these materials. Figure 1 compares the temperature range of current and future catalytic processes. The temperature of the most conventional industrial processes based on petrochemistry does not exceed $650^{\circ} \mathrm{C}$. The highest operating temperature of methane steam reforming in $\mathrm{H}_{2}$ production is still less than $800^{\circ} \mathrm{C}$; however, the high-pressure steam significantly deteriorates catalysts and supports. ${ }^{2)}$ Thermal deactivation is more concerning in automotive catalysts,

\footnotetext{
Corresponding author: M. Machida; E-mail: machida@ kumamoto-u.ac.jp
}

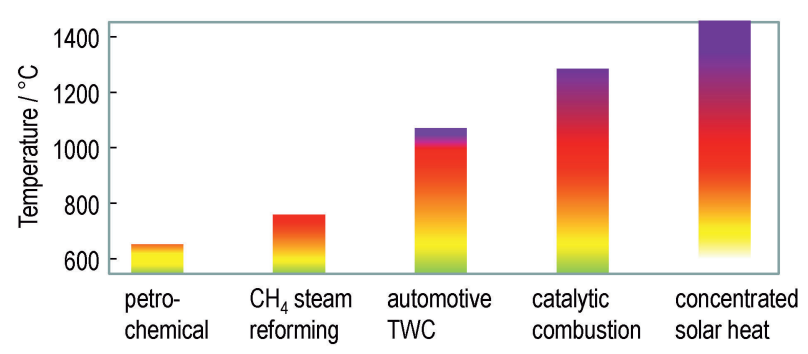

Fig. 1. Ranges of temperatures for current and future catalytic processes.

especially three-way catalysts (TWCs), which are used in gasoline-fueled engines. ${ }^{1)}$ In this process, several factors cause catalyst deactivation such as the large fluctuations in the operating temperature (from room temperature to more than $1,000^{\circ} \mathrm{C}$ ), gas velocity, and gas composition (due to reduction and oxidation). High-throughput catalytic combustors for gas turbines, where catalytic materials must retain as much surface area and activity as possible, are operated at high temperatures $\left.\left(800-1,200^{\circ} \mathrm{C}\right) .{ }^{3}\right)$ Thermochemical cycles in solar fuel production processes using 
concentrated solar radiation as a source of heat also require thermally stable catalytic materials. This process is a promising carbon-free energy production, given that the natural availability of solar radiation is remarkably larger than that of any other renewable energy source. At high solar flux concentration ratios $(\geq 1,000$ suns), which are defined as the ratios of concentrated irradiation intensity versus the direct normal beam insolation ( 1 sun is equivalent to the normal beam insolation of $1 \mathrm{~kW} \mathrm{~m}^{-2}$ ), high temperatures exceeding $1,000^{\circ} \mathrm{C}$ are available. ${ }^{4), 5)}$ In addition to thermal stability, catalytic materials should have the ability to withstand corrosive chemical substances, for example, strong acids, in some processes. Thus, catalytic materials with high heat and/or corrosion resistance are essential in the fields of environmental protection and clean energy production.

In this article, the development of thermally stable materials featuring catalytic functions is reviewed based on recent publications from the author's research group. The review highlights the heat- and corrosion-resistant catalysts for automotive pollution control and solar thermochemical energy production, respectively. The materials used in each field can be divided into two categories for convenience: supported platinum group metal (PGM) catalysts and nonPGM oxide-based catalysts. PGMs are among the most active catalysts available. However, because of their limited supplies and the increasing demands, several challenges are facing the development of PGM-free catalysts based on base metals with high activity and stability to replace PGMs. The structure-function relationships of these catalytic materials are discussed with emphasis on ways to enhance their thermal/corrosion resistance.

\section{Heat-resistant catalytic materials for automotive emission control}

\subsection{PGM catalysts}

In the most common supported PGM catalysts, which are used as automotive TWCs, the loss in the catalytic surface area due to sintering when the catalyst is exposed to high-temperature $\left(\sim 1,000^{\circ} \mathrm{C}\right)$ exhausts is a main cause of thermally induced deactivation. Sintering via particle growth at elevated temperatures is thermodynamically unavoidable. Particle growth when the temperature is not sufficiently high for vapor transport can occur via two possible mechanisms: particle migration and atomic/molecular migration. ${ }^{6), 7)}$ Particle migration involves the migration of PGM particles over the support surface followed by collision and coalescence. Atomic/molecular migration involves the detachment of metal atoms/molecules from particles followed by their migration over the support surface until they are captured by larger particles. The latter mechanism is also used for the explanation of redispersion of supported metals, which emerges for the system enabling strong metal-support bonding. To suppress sintering, an interfacial bonding should be established between the PGM particles and the support surface to provide an anchoring effect. ${ }^{8), 9)}$ Therefore, an efficient and robust support material to produce optimum metal-support inter-

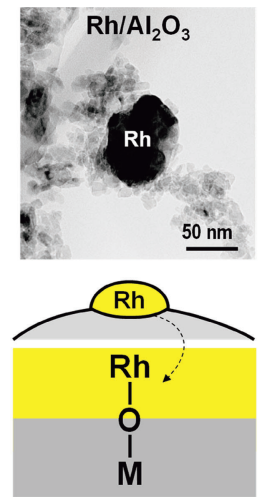

solid reactions
oxidizing

slow

fast

low

low

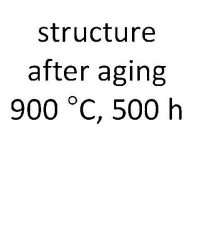

interfacial bonding

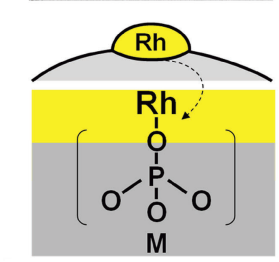

no solid reactions

reducing/oxidizing

atmosphere

reduction of $\mathrm{RhO}_{\mathrm{x}}$

fast

slow

high

high
Fig. 2. A comparison of local structure, stability, redox property, and electronic property between Rh catalysts supported on oxide and phosphate supports. ${ }^{17}$

actions can significantly reduce the loading of PGM without affecting the performance.

The author's research group studied fundamental and practical aspects of the anchoring effect of $\mathrm{Rh}$ catalysts supported on metal phosphates compared with those supported on conventional metal oxides. ${ }^{10)-17)}$ Figure 2 shows schematic representations of the local structure, electronic structure, and redox properties of Rh nanoparticles supported on metal phosphate and metal oxide. Metal phosphates stabilize $\mathrm{Rh}$ nanoparticles on their surface via an $\mathrm{Rh}-\mathrm{O}-\mathrm{P}$ interfacial bond. By contrast, $\mathrm{Rh}-\mathrm{O}-\mathrm{M}$ bonds are formed on metal oxides. This was detected using extended X-ray absorption fine structure (EXAFS) analysis. The $\mathrm{Rh}-\mathrm{O}-\mathrm{P}$ interfacial bond induces no deactivation via solid-state reactions. However, $\mathrm{Rh}-\mathrm{O}-\mathrm{M}$ causes undesired solid-state reactions, which yield a deactivated phase as can be seen at the interface of $\mathrm{RhO}_{\mathrm{x}}$ and $\gamma-\mathrm{Al}_{2} \mathrm{O}_{3}$ under oxidizing atmosphere (Fig. 2). The deactivated phase contains very large agglomerates $(>50 \mathrm{~nm})$ that indicate a significant sintering. By contrast, $\mathrm{Rh}$ nanoparticles highly dispersed in $\mathrm{Rh} / \mathrm{AlPO}_{4}$ remained even after thermal aging. These thermostable $\mathrm{Rh}$ nanoparticles are responsible for the preserved catalytic activity, which is superior to $\mathrm{Rh} / \gamma$ $\mathrm{Al}_{2} \mathrm{O}_{3}$. The differences in the local structure and electronic state between $\mathrm{Rh} / \mathrm{AlPO}_{4}$ and $\mathrm{Rh} / \gamma-\mathrm{Al}_{2} \mathrm{O}_{3}$ were also investigated using periodic density functional theory calculations. ${ }^{16)}$ The $\mathrm{Rh}$ adsorption energy at the $\mathrm{P}-\mathrm{O}$ site on the $\mathrm{AlPO}_{4}$ surface was larger than that at the Al-O site on the $\gamma-\mathrm{Al}_{2} \mathrm{O}_{3}$ surface because the charge transfer from $\mathrm{Rh}$ to the $\mathrm{AlPO}_{4}$ surface is considerably larger.

The nature of the anchoring effect also influences the electronic structures and redox properties of supported Rh catalysts. ${ }^{13)}$ Because of the covalency of the Rh-O-P 
bond, $\mathrm{Rh}$ oxide is readily reduced to metallic $\mathrm{Rh}$ with a higher catalytic activity, whereas the reduction of Rh oxide on metal oxide supports is more difficult as the anchoring effect increases. Furthermore, Rh metal shows a higher tolerance to reoxidation when supported on metal phosphates because the $\mathrm{Rh}-\mathrm{O}-\mathrm{P}$ bond is preserved under reducing atmospheres. The electron deficiency of $\mathrm{Rh}$ metal also affects its catalytic properties, and the extent of the electron deficiency can be tuned by replacing the metal in the metal phosphate group with a higher basicity metal. This unusual redox characteristic enhances the $\mathrm{NO}_{\mathrm{x}}$ conversion efficiency under lean conditions. ${ }^{15)}$ Additionally, the $\mathrm{Rh} / \mathrm{AlPO}_{4}$ catalyst exhibits a much higher resistance to sulfur and phosphorus poisoning compared with $\mathrm{Rh} / \gamma$ $\mathrm{Al}_{2} \mathrm{O}_{3}$. ${ }^{18)}$

\subsection{Non-PGM catalysts}

Since PGM-based TWCs were commercialized in 1971, numerous materials have been extensively studied as possible alternatives to PGM. Nevertheless, the replacement of PGM-based TWCs by non-PGM transition metal elements has not been successful. The base metal oxide catalysts are sensitive to the presence of water vapor, hightemperature aging, and reducing/oxidizing atmospheres. All these factors may considerably alter the catalytic activity, which renders the development of PGM-free TWC a highly challenging task. The author and coworkers have tackled this problem by combining several metal elements with different characteristics to form PGM-free TWC.

The first example is the thermally stable $\mathrm{Cr}-\mathrm{Cu}$ catalysts embedded in a $\mathrm{CeO}_{2}$ surface structure. ${ }^{19), 20)} \mathrm{A}$ catalyst loaded with only $0.14 \mathrm{wt} \%$ metal $(\mathrm{Cr}+\mathrm{Cu})$ and thermally aged at $900^{\circ} \mathrm{C}$ for $25 \mathrm{~h}$ exhibited catalytic performance comparable with those of PGM catalysts in the $\mathrm{CO}-\mathrm{O}_{2}$ and CO-NO reactions. As shown in Fig. 3, this thermal aging generated a multicomponent surface-embedded structure, which comprises $\mathrm{Cu}^{+}, \mathrm{Cr}^{3+}, \mathrm{Ce}^{3+} / \mathrm{Ce}^{4+}$, and an oxygen vacancy $\left(\mathrm{V}_{\mathrm{O}}\right)$. A combined experimental and theoretical study revealed the role of each element and the catalytic mechanisms regulating the $\mathrm{CO}-\mathrm{NO}$ reaction. ${ }^{21)}$ It was found that the presence of $\mathrm{Cr}$ around atomically dispersed $\mathrm{Cu}$ affects the oxidation state and coordination environment of $\mathrm{Cu}$. Thus, in addition to the $\mathrm{V}_{\mathrm{O}}$ formation, $\mathrm{Cu}^{+}$ formed in asymmetric three-fold $\mathrm{O}$ coordination sites plays an important role as efficient catalytic sites for chemisorption and oxidation of CO. This enhances the spin density accumulated on the adjacent $\mathrm{Ce}$ site, improving the $\mathrm{NO}$ adsorption thereon. Next, the oxygen of adsorbed NO is trapped by $\mathrm{V}_{\mathrm{O}}$. When this occurs on the neighboring $\mathrm{Ce}$ sites, it facilitates the formation of ON-NO dimer because the reaction pathways to produce $\mathrm{N}_{2}$ are possible at a low energy barrier. Overall, this reaction proceeds via the Mars-van Krevelen mechanism, where adsorbed $\mathrm{CO}$ molecules react with a lattice oxygen to release a $\mathrm{CO}_{2}$ and resultant oxygen vacancies are replenished when adsorbed NO molecules were reduced to $\mathrm{N}_{2}$. The synergy of the multicomponent surface may help explain the significantly greater catalytic activity of $\mathrm{Cr}-\mathrm{Cu} / \mathrm{CeO}_{2}$ compared with those of $\mathrm{Cu} / \mathrm{CeO}_{2}, \mathrm{Cr} / \mathrm{CeO}_{2}$, and PGM catalysts. The use of $\mathrm{CeO}_{2}$-based support has attracted considerable attention not only for non-PGMs but also for PGMs because metalsupport interactions allow synergistic oxidation/reduction of both the metal and $\mathrm{CeO}_{2}$, which enhances the catalytic performance and oxygen release/storage functions. ${ }^{22)-26)}$

The second example is a bulk solid solution based on multicomponent spinel-type oxides whose composition is expressed by $\mathrm{Cu}_{0.05} \mathrm{Ni}_{0.95} \mathrm{Al}_{1.8} \mathrm{Cr}_{0.2} \mathrm{O}_{4}{ }^{27), 28)}$ This quaternary oxide exhibited an NO reduction activity under practical TWC condition in the presence of $\mathrm{H}_{2} \mathrm{O}(\geq 5 \%)$ even after thermal aging at $900{ }^{\circ} \mathrm{C}$. By contrast, most conventional binary and/or ternary spinel oxides lose the NO reduction activity in the presence of water vapor and/or after high-temperature aging. Structural analysis using EXAFS and X-ray Rietveld analysis revealed that $\mathrm{Cu}$ and $\mathrm{Cr}$ tend to occupy the tetrahedral and octahedral sites, respectively, whereas $\mathrm{Ni}$ and $\mathrm{Al}$ are distributed across both sites [Fig. 4(a)]. Transmission electron microscope (TEM) analysis suggests that monodisperse solid solution

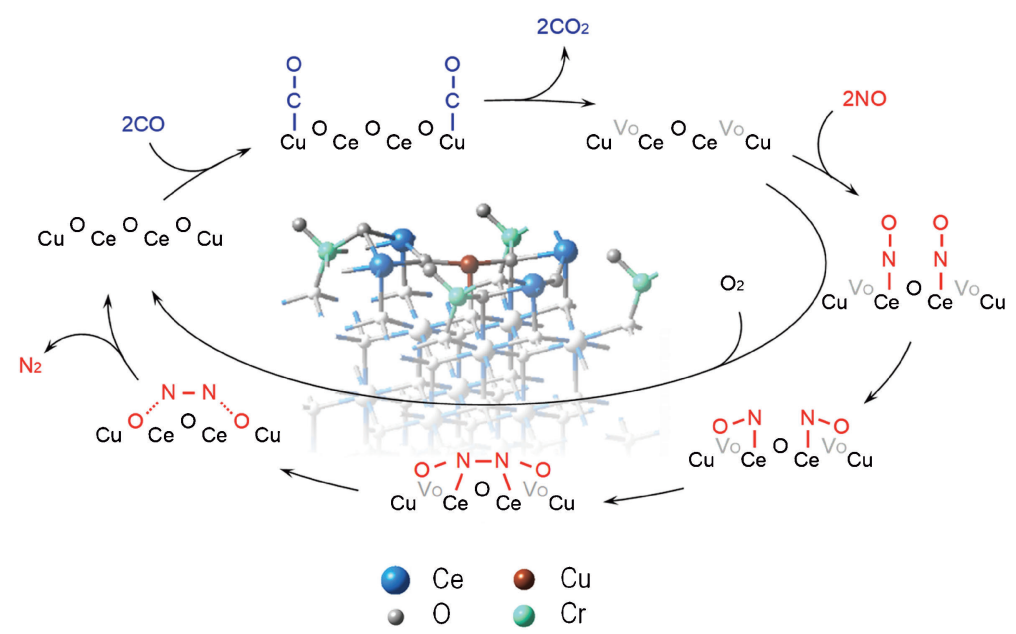

Fig. 3. The surface structure model of $\mathrm{Cr}-\mathrm{Cu}$-embedded $\mathrm{CeO}_{2}$ and a possible reaction mechanism of the $\mathrm{CO}-$ NO reaction. ${ }^{21)}$ 
(a)
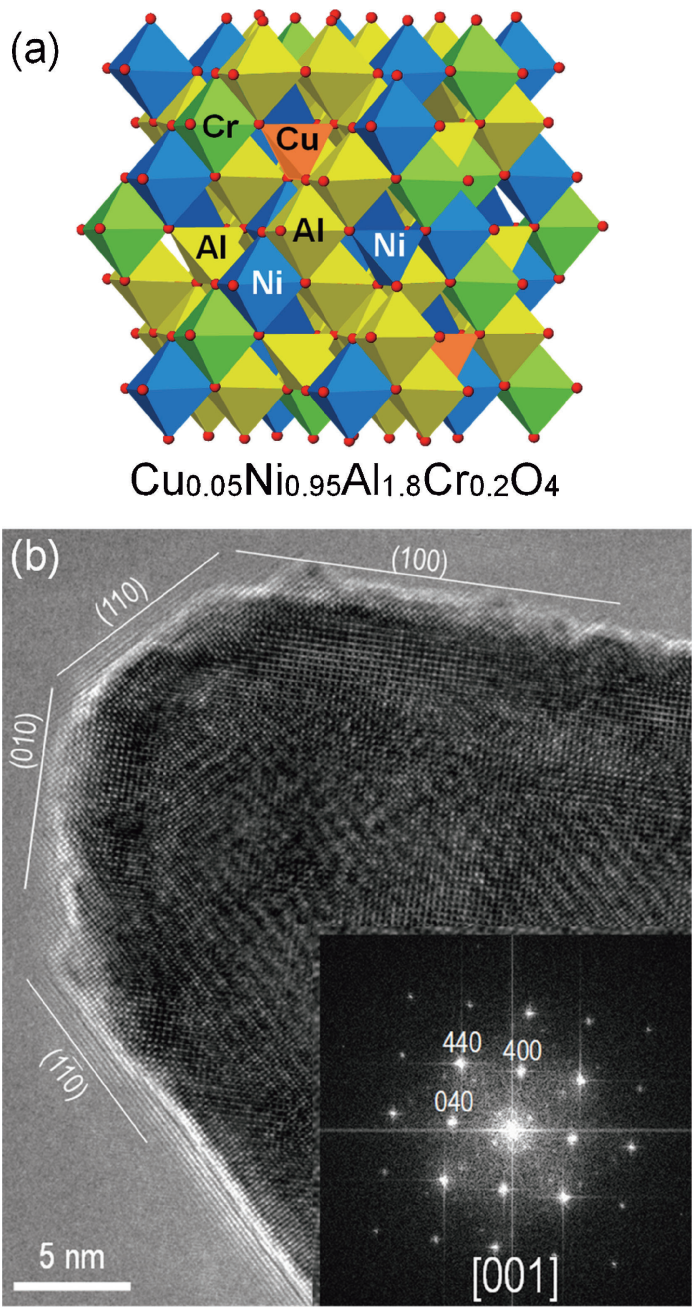

(c)

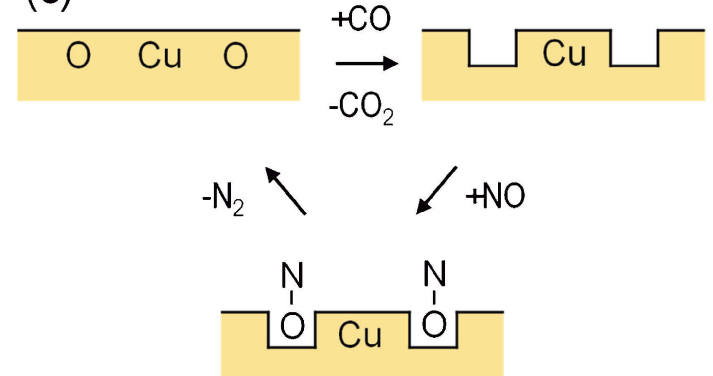

Fig. 4. The crystal structure and a TEM image of multicomponent spinel oxide solid solution $\mathrm{Cu}_{0.05} \mathrm{Ni}_{0.95} \mathrm{Al}_{1.8} \mathrm{Cr}_{0.2} \mathrm{O}_{4}{ }^{27}$ )

particles are composed of low-index facets, such as $\{110\}$ and $\{100\}$, with significant surface roughness [Fig. 4(b)]. On the surface, the monovalent $\mathrm{Cu}$ in the tetrahedral site plays a key role in $\mathrm{CO}$ chemisorption, $\mathrm{V}_{\mathrm{O}}$ formation, and the subsequent NO reduction via the Mars-van Krevelen mechanism [Fig. 4(c)]. The partial replacement of $\mathrm{Cr}$ by $\mathrm{Al}$ increased the specific surface area from 7 to $36 \mathrm{~m}^{2} \mathrm{~g}^{-1}$, which is a common feature of the $\mathrm{NiAl}_{2} \mathrm{O}_{4}$-based spinel platform. $\mathrm{Cr}$ and $\mathrm{Ni}$ can promote $\mathrm{CO}-\mathrm{H}_{2} \mathrm{O}$ and $\mathrm{C}_{3} \mathrm{H}_{6}-\mathrm{O}_{2}$ reactions, respectively. A positive synergy between these different functionalities of the metal elements results in a high NO reduction activity under a wet gas stream. A similar combination of transition metals was found to have more efficient TWC activity when reduced to multicomponent alloy nanoparticles supported on $\gamma-\mathrm{Al}_{2} \mathrm{O}_{3}$ by $\mathrm{H}_{2}$ at $900{ }^{\circ} \mathrm{C} .{ }^{29)}$

\section{Corrosion-resistant catalytic materials for solar thermal energy conversion}

Solar fuels production can be defined as hightemperature endothermic reactions that take place via solar thermochemical cycles to produce energy carriers such as $\mathrm{H}_{2}$ and $\mathrm{NH}_{3} .{ }^{30), 31)}$ The sulfur-iodine process is a wellknown example of thermochemical water splitting, which consists of sulfuric decomposition (1), hydrogen iodide decomposition (2), and the Bunsen reaction (3).

$$
\begin{aligned}
& \mathrm{H}_{2} \mathrm{SO}_{4} \rightarrow \mathrm{H}_{2} \mathrm{O}+\mathrm{SO}_{2}+1 / 2 \mathrm{O}_{2} \\
& 2 \mathrm{HI} \rightarrow \mathrm{H}_{2}+\mathrm{I}_{2} \\
& \mathrm{SO}_{2}+\mathrm{I}_{2}+2 \mathrm{H}_{2} \mathrm{O} \rightarrow \mathrm{H}_{2} \mathrm{SO}_{4}+2 \mathrm{HI}
\end{aligned}
$$

Thermochemical cycles of the sulfur family are a series of consecutive chemical reactions that recycle sulfur as the key element that occurs in different compounds during the change in the oxidation state. Sulfuric acid decomposition into $\mathrm{SO}_{2}$ is among the most advanced and reliable reactions as an oxygen generating step in water splitting.

$$
\begin{gathered}
\mathrm{H}_{2} \mathrm{SO}_{4}(\mathrm{aq}) \rightarrow \mathrm{H}_{2} \mathrm{O}(\mathrm{g})+\mathrm{SO}_{3}(\mathrm{~g}) \quad \Delta H=231 \mathrm{~kJ} \mathrm{~mol}^{-1} \\
\mathrm{SO}_{3}(\mathrm{~g}) \rightarrow \mathrm{SO}_{2}(\mathrm{~g})+1 / 2 \mathrm{O}_{2}(\mathrm{~g}) \quad \Delta H=99 \mathrm{~kJ} \mathrm{~mol}^{-1}
\end{gathered}
$$

$\mathrm{SO}_{3}$ decomposition (5) requires catalysts operating at temperatures $\geq 600^{\circ} \mathrm{C}$. Thus, other important factors, such as tolerance to high-temperature and corrosive environment, which severely damage most conventional catalytic materials within a short period, are required in addition to the catalytic activity. The formation of stable sulfates under the reaction conditions is a common problem for metal oxides used as active components and support materials. In fact, the deactivation of metal oxides due to sulfate formation becomes more significant at lower reaction temperatures. To solve this problem, the author's research group has developed two classes of state-of-the-art catalytic materials for solar-driven $\mathrm{SO}_{3}$ decomposition: a series of supported PGM catalysts and a non-PGM catalyst based on a series of supported molten vanadates.

\subsection{PGM catalysts}

The catalytic activity of $\mathrm{PGM}$ for $\mathrm{SO}_{3}$ decomposition decreases in the following order: $\mathrm{Pt}>\mathrm{Pd}>\mathrm{Rh}>\mathrm{Ir}>$ $\mathrm{Ru}^{32)}$ Supported Pt catalysts are mostly studied for lowtemperature processes $\left(\sim 600^{\circ} \mathrm{C}\right)$. The $\mathrm{SO}_{3}$ decomposition reaction steps using $\mathrm{Pt}$ can be described as follows:

$$
\begin{aligned}
& \mathrm{SO}_{3 \mathrm{~s}} \rightarrow \mathrm{SO}_{2 \mathrm{~s}}+\mathrm{O}_{\mathrm{s}} \\
& \mathrm{SO}_{2 \mathrm{~s}} \rightarrow \mathrm{SO}_{2} \\
& \mathrm{O}_{\mathrm{s}}+\mathrm{O}_{\mathrm{s}} \rightarrow \mathrm{O}_{2}
\end{aligned}
$$

where the subscript "s" denotes adsorbed species.

The activity can be determined by the rate of the dissociation of adsorbed $\mathrm{SO}_{3}$ species (6) and the removal rate 
(a)
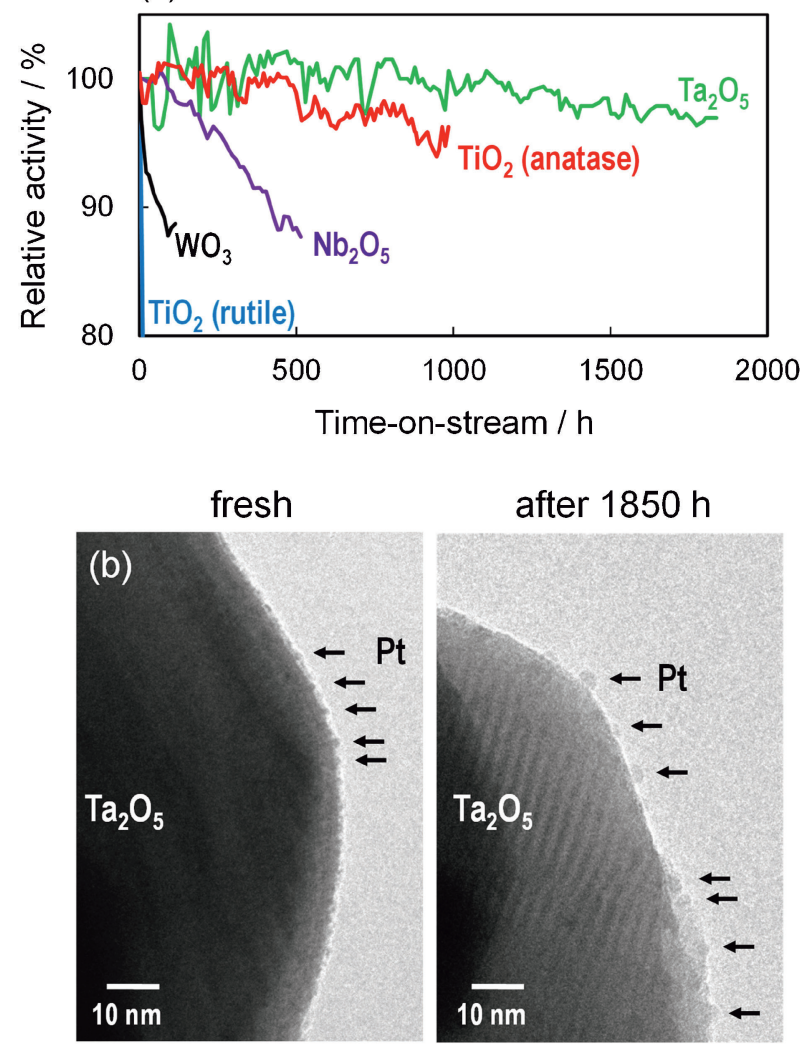

Fig. 5. (a) Results of catalyst stability tests at $600^{\circ} \mathrm{C}$ for $\mathrm{Pt}$ catalysts supported on $\mathrm{SO}_{3}$-resistant metal oxides and (b) TEM images of $\mathrm{Pt} / \mathrm{Ta}_{2} \mathrm{O}_{5}$ before and after the stability test. ${ }^{35)}$

of the decomposition products from the surface of the metal nanoparticles, (7) and (8). The rate of reaction (6) is always higher than those of reactions (7) and (8). ${ }^{32)} \mathrm{Pt}$ is therefore more efficient when its metallic state is favored over its oxidized states ( $\mathrm{PtO}$ and/or $\mathrm{PtO}_{2}$ ). Metallic $\mathrm{Pt}$ surfaces are more efficient than the oxidized Pt surfaces for the detachment of $\mathrm{O}$ atoms from $\mathrm{SO}_{3}$ species (6). The selection of support materials is key to ensure the activity and long-term stability of the Pt catalysts. Although $\gamma$ $\mathrm{Al}_{2} \mathrm{O}_{3}$ is the most used support for industrial applications, its instability in the presence of $\mathrm{SO}_{3}$ leads to the formation of $\mathrm{Al}_{2}\left(\mathrm{SO}_{4}\right)_{3}$ overlayers at $\sim 600{ }^{\circ} \mathrm{C}$, which blocks the access to the active Pt sites. Thus, stable Pt catalysts can be prepared by dispersing $\mathrm{Pt}$ onto $\mathrm{SO}_{3}$-resistant support materials, such as $\mathrm{TiO}_{2}, \mathrm{Nb}_{2} \mathrm{O}_{5}, \mathrm{Ta}_{2} \mathrm{O}_{5}$, and $\mathrm{WO}_{3}$. $\mathrm{TiO}_{2}$ has been studied extensively. However, most studies focused only on the rutile phase, which is thermodynamically stable at high temperatures $\left(\sim 800^{\circ} \mathrm{C}\right)$. The author and coworkers found that $\mathrm{Pt}$ supported on anatase is much more active and stable at a moderate temperature of $600^{\circ} \mathrm{C}$ compared with that on rutile [Fig. 5(a)]. ${ }^{33)}$ At this temperature, $\mathrm{Pt}$ is mainly present in the active metallic state on anatase $\mathrm{TiO}_{2}$, whereas less-active $\mathrm{Pt}$ oxides $\left(\mathrm{PtO}_{2}\right.$ and $\left.\mathrm{PtO}\right)$ are dominant on rutile $\mathrm{TiO}_{2}$. This stark contrast can be attributed to the greater interfacial formation energy, which stabilizes the oxidized states of $\mathrm{Pt}$ on rutile. ${ }^{34)}$ During continuous catalytic testing for $1,000 \mathrm{~h}$ at $600^{\circ} \mathrm{C}, \mathrm{Pt} /$ anatase exhibited activity loss of approximately $4 \%$ (from the initial activity). The most stable $\mathrm{SO}_{3}$ decomposition performance at $600{ }^{\circ} \mathrm{C}$ was reported to be that of Pt supported on $\mathrm{Ta}_{2} \mathrm{O}_{5} .{ }^{35)}$ The long-term stability of $\mathrm{Pt} / \mathrm{Ta}_{2} \mathrm{O}_{5}$ for the $\mathrm{SO}_{3}$ decomposition reaction at $600^{\circ} \mathrm{C}$ was demonstrated more than $1,800 \mathrm{~h}$, in which the activity loss was less than $1.5 \%$ per 1,000 h [Fig. 5(a)]. The TEM images in Fig. 5(b) indicate that the Pt particles highly dispersed in the fresh catalysts are only slightly grown in size from $\leq 2$ to $3-5 \mathrm{~nm}$. This suppression of $\mathrm{Pt}$ sintering is due to a strong anchoring effect of $\mathrm{Ta}_{2} \mathrm{O}_{5}$. It is suggested that the interaction between the Pt metal and a $\mathrm{Ta}_{2} \mathrm{O}_{5}$ support may increase the electronic density of $\mathrm{Pt}$, which affects the dissociation ability of the S-O bond in the reaction (6). ${ }^{36)}$ These characteristics enhance the catalytic activity and stability even under a strong oxidizing atmosphere containing $\mathrm{SO}_{3}$ and $\mathrm{O}_{2}$.

\subsection{Non-PGM catalysts}

Metal oxides have been highlighted as economically viable catalysts. ${ }^{37)}$ However, their activity is not equal, and it follows this order: $\mathrm{Pt}>\mathrm{Cr}_{2} \mathrm{O}_{3}>\mathrm{Fe}_{2} \mathrm{O}_{3}>\mathrm{CuO}>$ $\mathrm{CeO}_{2}>\mathrm{NiO}>\mathrm{Al}_{2} \mathrm{O}_{3} \cdot{ }^{38)}$ None of these oxides and their composites satisfy the activity requirements of processes below $650{ }^{\circ} \mathrm{C}$. The $\mathrm{SO}_{3}$ decomposition on metal oxide catalysts $\left(\mathrm{MO} / \mathrm{MO}_{2}\right)$ proceeds via a sulfate intermediate as follows: ${ }^{38)}$

$$
\begin{aligned}
& \mathrm{MO}+\mathrm{SO}_{3} \rightarrow\left(\mathrm{MSO}_{4}\right) \rightarrow \mathrm{MO}_{2}+\mathrm{SO}_{2} \\
& \mathrm{MO}_{2} \rightarrow \mathrm{MO}+1 / 2 \mathrm{O}_{2}
\end{aligned}
$$

According to reaction (9), metal oxides with a weak basicity interact very weakly with $\mathrm{SO}_{3}$, resulting in a low rate of formation of surface sulfate $\left(\mathrm{MSO}_{4}\right)$. By contrast, metal oxides with high basicity yield very stable sulfates, which makes their decomposition a rate-determining step. The subsequent step (10) suggests that oxygen removal after the desorption of $\mathrm{SO}_{2}$ is a key step for $\mathrm{SO}_{3}$ decomposition.

Vanadates supported on porous $\mathrm{SiO}_{2}$ supports are another class of candidates for solar-driven $\mathrm{SO}_{3}$ decomposition catalysts. This type shows $\mathrm{SO}_{3}$ decomposition activities approaching those of $\mathrm{Pt}$ catalysts at a moderate temperature range. Unlike solid metal oxide catalysts, vanadate-based catalysts, including $\mathrm{Cu}-\mathrm{V}, \mathrm{K}-\mathrm{V}$, and $\mathrm{Cs}-\mathrm{V}$, can be regarded as molten-phase catalysts because their melting points are nearly equal to or lower than the reaction temperature of $\mathrm{SO}_{3}$ decomposition $\left.\left(\sim 650{ }^{\circ} \mathrm{C}\right) .{ }^{39)}-43\right)$ Because vanadates are resistant to sulfate formation, the catalytic activity can be enhanced by supporting the catalyst on mesoporous $\mathrm{SiO}_{2}$ followed by thermal aging above the vanadate melting point, which allows the molten phase to penetrate the $\mathrm{SiO}_{2}$ mesopores. ${ }^{40)}$ The simultaneous dissolution-reprecipitation of $\mathrm{SiO}_{2}$ in the melt converts the mesopores to macroporous cavities whose surface is completely covered with a thin liquid layer of active vanadate. A mechanism for the accelerated catalytic $\mathrm{SO}_{3}$ decomposition on the supported molten copper vanadate catalyst was proposed (Fig. 6). ${ }^{41)}$ On the surface of the molten vanadate, $\mathrm{SO}_{3}$ adsorption on $\mathrm{Cu}$ oxide species generates $\mathrm{Cu}-\mathrm{SO}_{4}$ species because it is thermodynamically favored 

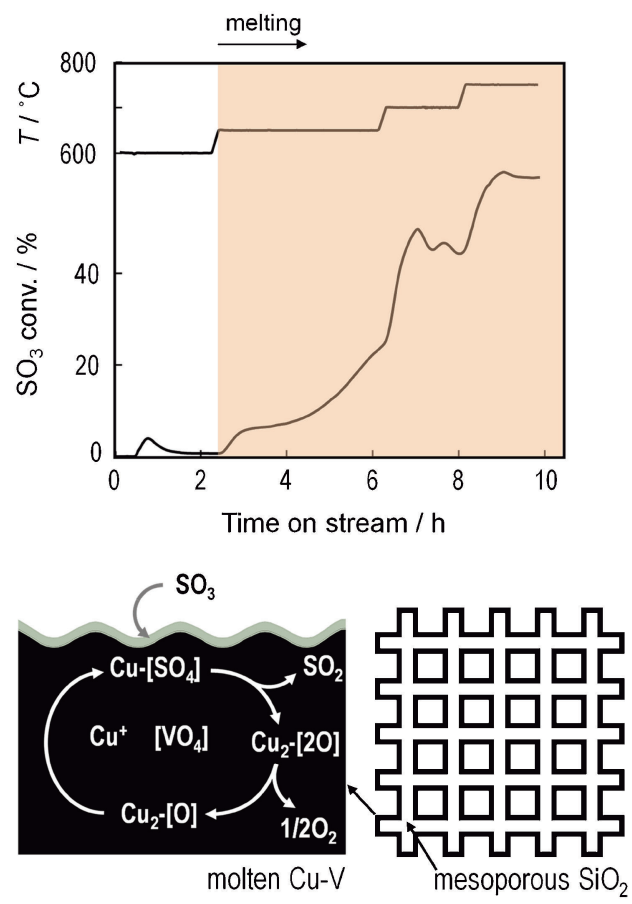

Fig. 6. Catalytic $\mathrm{SO}_{3}$ conversion over molten $\mathrm{Cu}-\mathrm{V}$ phase supported on mesoporous $\mathrm{SiO}_{2}$ and a possible reaction scheme. Reproduced from Reference ${ }^{41)}$ with permission from The Royal Society of Chemistry.

around $650{ }^{\circ} \mathrm{C}$. Here one important contribution of the liquid surface to the catalytic reaction is the dissolution of $\mathrm{Cu}-\left[\mathrm{SO}_{4}\right]$ species in the molten phase, leaving the liquid surface with more vacant sites for further $\mathrm{SO}_{3}$ adsorption. Because the molten phase comprises tetrahedral $\mathrm{VO}_{4}$ and $\mathrm{Cu}^{+}$, the dissolved $\left[\mathrm{SO}_{4}\right]$ is immediately reduced to evolve $\mathrm{SO}_{2}$ followed by oxygen release from the reoxidized $\mathrm{Cu}^{2+}$ oxides $\left(\mathrm{Cu}_{2}-[2 \mathrm{O}]\right)$. The resulting free monovalent copper oxide species $\left(\mathrm{Cu}_{2}-[\mathrm{O}]\right)$ diffuses back to the liquid surface, where the reaction with $\mathrm{SO}_{3}$ regenerates $\mathrm{Cu}-\left[\mathrm{SO}_{4}\right]$. Consequently, the molten vanadate enables fast $\mathrm{SO}_{3}$ capture and decomposition to $\mathrm{SO}_{2} / \mathrm{O}_{2}$ cycles.

\section{Summary and outlook}

Based on the recent publications of the author's research group, this review article discusses several examples of heat- and corrosion-resistant catalytic materials, focusing on automotive pollution control and solar thermochemical energy production. Designing materials that can overcome the tradeoff relationship between surface area and stability against sintering to obtain catalysts with high catalytic activity, thermal stability, and/or corrosion tolerance represents a challenge. Ceramic material research and development play a key role in overcoming this challenge by controlling multiscale structures and physicochemical functions of metals, metal oxides, and their interfaces. Conventional ceramic research has focused on gaining systematized knowledge about sintering into a dense solid. Conversely, it gains practical knowledge on how to prevent sintering of nanoparticles with large surface areas. Future research in heat- and corrosion-resistant catalysts should be oriented toward the reduction in PGM use because of their limited supplies and the increasing demands for them in other applications. Thus, understanding the nature of each metal in its different states, phases, and structures is of primary importance. Therefore, further possible combinations should be considered to achieve the highest catalytic performance and thermal/corrosion stability.

Acknowledgments Parts of this study were supported by the Ministry of Education, Culture, Sports, Science and Technology (MEXT) program, "Elements Strategy Initiative to Form Core Research Center" (JPMXP0112101003) and the Council for Science, Technology, and Innovation (CSTI), Cross-ministerial Strategic Innovation Promotion Program (SIP), “energy carrier" (Funding agency: JST).

\section{References}

1) R. M. Heck, R. J. Farrauto and S. T. Gulati, "Catalytic Air Pollution Control: Commercial Technology”, Wiley, Hoboken (1995).

2) J. R. Rostrup-Nielsen, Catal. Sci. Technol., 5, 1-117 (1984).

3) K. Sekizawa, K. Eguchi, H. Widjaja, M. Machida and H. Arai, Catal. Today, 28, 245-250 (1996).

4) A. Steinfeld, Sol. Energy, 78, 603-615 (2005).

5) T. Hahm, H. Schmidt-Traub and B. Lessmann, Sol. Energy, 65, 33-41 (1999).

6) P. Wynblatt and T. M. Ahn, Sintering and Catalysis, in "Crystallite Sintering and Growth in Supported Catalysts", Ed. by G. C. Kuczynski, Plenum Press, New York (1975) pp. 83-106.

7) S. E. Wanke, Sintering and Catalysis, in "Sintering of Supported Metal Catalysts: Application of a Mechanistic Model to Experimental Data", Ed. by G. C. Kuczynski, Plenum Press, New York (1975) pp. 107116.

8) Y. Nagai, T. Hirabayashi, K. Dohmae, N. Takagi, T. Minami, H. Shinjoh and S. i. Matsumoto, J. Catal., 242, 103-109 (2006).

9) Y. Nagai, K. Dohmae, Y. Ikeda, N. Takagi, T. Tanabe, N. Hara, G. Guilera, S. Pascarelli, M. A. Newton, O. Kuno, H. Jiang, H. Shinjoh and S. Matsumoto, Angew. Chem. Int. Edit., 47, 9303-9306 (2008).

10) M. Machida, K. Murakami, S. Hinokuma, K. Uemura, K. Ikeue, M. Matsuda, M. Chai, Y. Nakahara and T. Sato, Chem. Mater., 21, 1796-1798 (2009).

11) K. Ikeue, K. Murakami, S. Hinokuma, K. Uemura, D. Zhang and M. Machida, B. Chem. Soc. Jpn., 83, 291297 (2010).

12) M. Machida, S. Minami, K. Ikeue, S. Hinokuma, Y. Nagao, T. Sato and Y. Nakahara, Chem. Mater., 26, 5799-5805 (2014).

13) M. Machida, S. Minami, H. Yoshida, S. Hinokuma, Y. Nagao, T. Sato and Y. Nakahara, J. Phys. Chem. C, 119, 373-380 (2015).

14) M. Machida, T. Eidome, S. Minami, H. P. Buwono, S. Hinokuma, Y. Nagao and Y. Nakahara, J. Phys. Chem. C, 119, 11653-11661 (2015).

15) Y. Nagao, Y. Nakahara, T. Sato, H. Iwakura, S. Takeshita, S. Minami, H. Yoshida and M. Machida, ACS Catal., 5, 1986-1994 (2015).

16) M. Matsui, M. Machida and S. Sakaki, J. Phys. Chem. 
C, 119, 19752-19762 (2015).

17) M. Machida, Chem. Rec., 16, 2219-2231 (2016).

18) H. P. Buwono, S. Minami, K. Uemura and M. Machida, Ind. Eng. Chem. Res., 54, 7233-7240 (2015).

19) H. Yoshida, N. Yamashita, S. Ijichi, Y. Okabe, S. Misumi, S. Hinokuma and M. Machida, ACS Catal., 5, 6738-6747 (2015).

20) H. Yoshida, Y. Okabe, S. Misumi, H. Oyama, K. Tokusada, S. Hinokuma and M. Machida, J. Phys. Chem. C, 120, 26852-26863 (2016).

21) K. Koizumi, H. Yoshida, M. Boero, K. Tamai, S. Hosokawa, T. Tanaka, K. Nobusada and M. Machida, Phys. Chem. Chem. Phys., 20, 25592-25601 (2018).

22) S. Hinokuma, H. Fujii, M. Okamoto, K. Ikeue and M. Machida, Chem. Mater, 22, 6183-6190 (2010).

23) S. Hinokuma, H. Fujii, Y. Katsuhara, K. Ikeue and M. Machida, Catal. Sci. Technol., 4, 2990-2996 (2014).

24) M. Machida, D. Kurogi and T. Kijima, J. Phys. Chem. $B, 107,196-202$ (2002).

25) M. Machida, A. Fujiwara, H. Yoshida, J. Ohyama, H. Asakura, S. Hosokawa, T. Tanaka, M. Haneda, A. Tomita, T. Miki, K. Iwashina, Y. Endo, Y. Nakahara, S. Minami, N. Kato, Y. Hayashi, H. Goto, M. Hori, T. Tsuda, K. Miura, F. Kimata and K. Iwachido, $A C S$ Catal., 9, 6415-6424 (2019).

26) K. Ito, K. Kishikawa, A. Watajima, K. Ikeue and M. Machida, Catal. Commun., 8, 2176-2180 (2007).

27) T. Hirakawa, Y. Shimokawa, W. Tokuzumi, T. Sato, M. Tsushida, H. Yoshida, S. Hinokuma, J. Ohyama and M. Machida, ACS Catal., 9, 11763-11773 (2019).

28) T. Hirakawa, W. Tokuzumi, Y. Shimokawa, T. Sato, H. Yoshida, J. Ohyama and M. Machida, J. Ceram. Soc. Jpn., 128, 906-911 (2020).

29) T. Hirakawa, Y. Shimokawa, W. Tokuzumi, T. Sato, M. Tsushida, H. Yoshida, J. Ohyama and M. Machida, $A C S$ Appl. Nano Mater., 3, 9097-9107 (2020).

30) O. Myagmarjav, J. Iwatsuki, N. Tanaka, H. Noguchi, Y. Kamiji, I. Ikuo, S. Kubo, M. Nomura, T. Yamaki, S.
Sawada, T. Tsuru, M. Kanezashi, X. Yu, M. Machida, T. Ishihara, H. Abekawa, M. Mizuno, T. Taguchi, Y. Hosono, Y. Kuriki, M. Inomata, K. Miyajima, Y. Inagaki and N. Sakaba, Int. J. Hydrogen Energ., 44, 19141-19152 (2019).

31) C. Sattler, M. Roeb, C. Agrafiotis and D. Thomey, Sol. Energy, 156, 30-47 (2017).

32) S. N. Rashkeev, D. M. Ginosar, L. M. Petkovic and H. H. Farrell, Catal. Today, 139, 291-298 (2009).

33) A. S. M. Nur, T. Matsukawa, S. Hinokuma and M. Machida, ACS Omega, 2, 7057-7065 (2017).

34) A. S. M. Nur, E. Funada, S. Kiritoshi, A. Matsumoto, R. Kakei, S. Hinokuma, H. Yoshida and M. Machida, J. Phys. Chem. C, 122, 662-669 (2018).

35) A. S. M. Nur, T. Matsukawa, E. Funada, S. Hinokuma and M. Machida, ACS Appl. Energy Mater., 1, 744-750 (2018).

36) E. V. Ramos-Fernández, B. Samaranch, P. Ramírez de la Piscina, N. Homs, J. L. G. Fierro, F. Rodríguez-Reinoso and A. Sepúlveda-Escribano, Appl. Catal. A-Gen., 349, 165-169 (2008).

37) N. R. Brown and S. T. Revankar, Int. J. Hydrogen Energ., 37, 2685-2698 (2012).

38) H. Tagawa and T. Endo, Int. J. Hydrogen Energ., 14, 11-17 (1989).

39) M. Machida, Y. Miyazaki, Y. Matsunaga and K. Ikeue, Chem. Commun., 47, 9591-9593 (2011).

40) M. Machida, T. Kawada, S. Hebishima, S. Hinokuma and S. Takeshima, Chem. Mater., 24, 557-561 (2012).

41) T. Kawada, T. Tajiri, H. Yamashita and M. Machida, Catal. Sci. Technol., 4, 780-785 (2014).

42) T. Kawada, M. Sueyoshi, T. Matsukawa, A. Ikematsu and M. Machida, Ind. Eng. Chem. Res., 55, 1168111688 (2016).

$43)$ A. S. M. Nur, T. Matsukawa, A. Ikematsu and M. Machida, ACS Appl. Energy Mater., 1, 2041-2047 (2018).

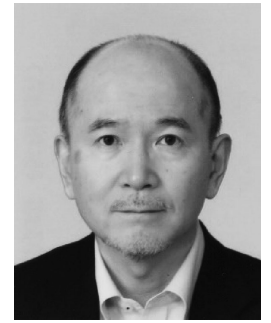

Masato Machida has been a Professor at the Faculty of Advanced Science and Technology, Kumamoto University since 2003. He received his Ph.D. in Engineering from Kyushu University in 1992. He started his professional career as an assistant professor at Kyushu University in 1988 and moved to Miyazaki University as an associate professor in 1992. He received the 75th CerSJ Awards for Academic Achievements in Ceramic Science and Technology in 2021. His main research focus is catalytic material chemistry for environmental protection and energy production. 